\title{
An epilogue to an emergency-trauma practicum
}

\author{
Allen Eugene Hong
}

Ajou Graduate School of Medicine, Suwon, Korea

Just when I was enjoying dinner at the restaurant in front of the hospital, I was called in by a cellphone message.

"A patient is arriving soon, please come to the heliport."

I rushed back to the hospital and scrambled to change into my uniform on the first floor of the trauma center. I put on goggles, a cap, and gloves, and went with colleagues up to the hospital rooftop where the heliport was.

The patient who arrived at the heliport was in his early 60s, with bandages wrapped around both arms and his head. We checked the patient's vital signs, consciousness, and the degree of systemic damage. Trauma team established intravenous lines in the vein, and maintained respiration by intubating with a respirator. The patient's consciousness and pain were reduced by anesthesia, according to the trauma bay protocol for assessing the patient condition. The trauma bay is an emergency room for trauma patients only. In the midst of all this, I inserted a Foley catheter.

Finally, both arms that had been given emergency care with bandages were exposed. "Oh my God..."
The left arm was cut off above the elbow, continuously bleeding, the muscles and bones exposed, and the right wrist was obliquely cut with only the thumb and index fingers left. Later, I heard that a steel wire, which was strung tightly at the factory, had snapped with a "bang," hitting both his arms and head like a whip.

That night, the operating room was open immediately for surgeons, nurses, and anesthesiologists, and I, a student, joined the surgery. As the air released from the blood-pressure cuff that used to press the left arm, bleeding from the artery began. The surgeon immediately found the artery and ligated it, then replaced the muscles and bone and covered them with skin. Surgery on the right hand went well, too.

Starting the following day, the patient's condition was checked during daily rounds. I removed the Foley catheter on the third day, when the patient was ambulatory, so that he could urinate by himself. I thought to myself, this patient would not be able to work; he'll become lethargic, spend the rest of his life in depression, and become a headache and potentially a target of hatred at home.

But this concern was unnecessary. The patient's
Received: November 6, 2017 • Revised: November 6, 2017 • Accepted: November 7, 2017 Corresponding Author: Allen Eugene Hong (https://orcid.org/0000-0002-8199-3715) Ajou University School of Medicine \& Graduate School of Medicine, 206 World cup-ro, Yeongtong-gu, Suwon 16499, Korea

Tel: +82.31.219.4496 Fax: +82.31.219.5059 email: allenhong@ajou.ac.kr
Korean J Med Educ 2017 Dec; 29(4): 287-288.

https://doi.org/10.3946/kjme.2017.75

eISSN: 2005-7288

(C) The Korean Society of Medical Education. All rights reserved. This is an open-access article distributed under the terms of the Creative Commons Attribution Non-Commercial License (http:// creativecommons.org/licenses/by-nc/3.0/), which permits unrestricted non-commercial use, distribution, and reproduction in any medium, provided the original work is properly cited. 
beautiful daughter arrived from a province and was caring for him with all her heart. She was always buoyant and energetic, without any worries or resentment. She was very thankful to the medical staff, saying, "I am just so grateful for the fact that my father survived."

The patient was recovering noticeably every day. On his last day in hospital, he was full of happiness, greeting the medical staff with a "Chupa Chups" lollipop in his mouth.

"My daughter gave it to me. Ha ha ha."

He was far from despair. Everybody was touched to tears by his happiness from a small candy. The love of his daughter for him, delivered in that small candy, was everything for him.

This experience occurred this year, during a 1 month practicum in emergency trauma for fourth-year medical school students at Ajou University School of Medicine. The practicum comprises 2 weeks of practice each at the emergency and trauma centers. In the emergency center, we see 30-40 patients with a medical specialist for more than 12 hours a day and, in the trauma center, we are on 24-hour duty every other day and see all incoming patients with the medical staff. There are no limitations on students' involvement, and skills such as intubation, wound dressing, catheter insertion, L-tube insertion, abdominal ultrasound, bagged mask pumping, electrocardiogram monitoring, arterial blood gas analysis, and cardiopulmonary resuscitation (CPR) -which we have learned during the past 6 years of medical school-are all allowed to be performed. Truth is that all medical staffs respected me as a doctor-to-be, not ignoring me as a burden, or interfering with medical treatments because I am a student. They encouraged me to participate actively in emergency care, and taught me to shout fiercely, "Consider this a real situation! Practice over and over!"

On the last day of the practicum, I was shedding warm tears of gratitude in my mind when my professor, who had been teaching the practicum, praised my efforts. "You've been working very hard," he said, with a truly affectionate facial expression, even though the professor himself must have been very tired after taking care of patients throughout the night, performing operations, and checking each and every patient in the intensive care unit.

Through this practicum, I feel, personally, that I am prepared as a "unit" who can run to a person collapsed in a public place and diagnose the patient's well-being in a real situation. I am prepared to perform $\mathrm{CPR}$, use automated external defibrillator, give instructions in an emergency situation, and provide emergency care for patients with trauma and excessive bleeding so that they will not die on the scene.

The emergency/trauma practicum provided me with an invaluable experience so that I can mature into a medical doctor, seeing emergency/trauma patients with passion. I know that, if I do not save the patient, the patient would die. This has provided me with intelligence to determine the most effective treatment in an unhurried, calm, and cool manner, and it has given me a quick hand, arriving first to help.

Meeting a good doctor is important for patients. Likewise, meeting a good educator is important for students. I hope more students have the chance to experience a practicum like this.

\section{ORCID:}

Allen Eugene Hong: https://orcid.org/0000-0002-8199-3715

Acknowledgements: None.

Funding: None.

Conflicts of interest: None. 